\title{
Alzira Vargas: A figura feminina e a articulação política nos governos de Getúlio Vargas.
}

\author{
Alzira Vargas: La figura femenina Y la articulación política em el \\ gobiernos de Getúlio Vargas \\ Alzira Vargas: A female figure and political articulation in the Getúlio \\ Vargas' governaments.
}

\author{
Lauren de Lacerda Nunes 1 \\ Roselaine Guedes Santos ${ }^{2}$ \\ Gladis Kunz Rosa ${ }^{3}$ \\ Karen Laís Roque ${ }^{4}$
}

\begin{abstract}
Resumo
O presente artigo visa abordar a trajetória histórica de Alzira Sarmanho Vargas na vida política do Brasil, nos governos de Getúlio Vargas (1930 - 1945 e 1951-1954), no sentido de mostrar sua atuação enquanto figura feminina significativa deste período. A metodologia utilizada consistiu de pesquisas em fontes originais, depositadas no Museu Getúlio Vargas, em São Borja-RS, no Centro de Pesquisa e Documentação de História Contemporânea do Brasil (CPDOC), da Fundação Getúlio Vargas, onde se encontra depositado o arquivo pessoal da Alzira Sarmanho Vargas. Concomitantemente, buscou-se referencial bibliográfico, no sentido de problematizar a condição da mulher, da política e da vida sociocultural do país no período histórico em que Alzira Vargas atuou. Dos documentos estudados, se abrem inúmeras possibilidades de interpretações e questionamentos sobre a real importância e participação de uma mulher que, sendo o pai, Getúlio Vargas, o presidente do país, tenha ela depositária da confiança e cumplicidade em momentos de extrema tensão, dúvidas e conflitos políticos nos âmbitos nacional e internacional. A quantidade de registros históricos, sejam eles documentos oficiais, jornais, revistas, vídeos ou em áudios não deixa margem para dúvidas quanto a presença constante e discreta da assessora Alzira Vargas e, em outros momentos, articuladora da nação com outros países. A possibilidade de conhecer esta mulher que, em ambiente predominantemente masculino ocupou espaços importantes em momentos históricos cruciais para o Brasil, instiga a busca de conhecê-la e problematizar sua trajetória enquanto figura feminina marcante na história do país, principal motivação da presente pesquisa.
\end{abstract}

Palavras-Chave: Alzira Vargas; gênero; Getúlio Vargas; mulher; política.

\section{Resumen}

1Doutora em Filosofia pela Universidade Federal de Santa Maria - UFSM, RS. Professora Adjunta da Universidade Federal do Pampa - UNIPAMPA campus São Borja, RS. E-mail: laurennunes@unipampa.edu.br.

2Especialista em Direito e Gestão Ambiental. Tecnóloga Ambiental - Resíduos Industriais. Acadêmica do Curso de Ciências Humanas - Licenciatura, da Universidade Federal do Pampa - UNIPAMPA, Campus São Borja, RS. E-mail: rose7866@hotmail.com.

3 Acadêmica do curso de Ciências Humanas - Licenciatura da Universidade Federal do Pampa - UNIPAMPA campus São Borja, RS. Bolsista do Projeto de Extensão: Construção e Desconstrução do gênero e sexualidade no currículo: tecendo perspectivas para uma educação multicultural. Membro do GEEP - Grupo de Pesquisa em Gênero, Ética, Educação e Política. E-mail: gladiswolff@gmail.com.

4 Acadêmica do curso de Ciências Humanas - Licenciatura da Universidade Federal do Pampa - UNIPAMPA campus São Borja, RS. E-mail: karenlaisroque@gmail.com. 
El presente artículo apunta a abordar la trayectoria histórica de Alzira Sarmanho Vargas en la vida política de Brasil, en los gobiernos de Getúlio Vargas (1930 - 1945 y 1951-1954), en el sentido de mostrar su actuación como figura femenina significativa de este período. La metodología utilizada consistió en investigaciones en fuentes originales, depositadas en el Museo Getúlio Vargas, en São Borja-RS, en el Centro de Investigación y Documentación de Historia Contemporánea de Brasil (CPDOC), de la Fundación Getúlio Vargas, donde se encuentra depositado el archivo personal de la empresa Alzira Sarmanho Vargas. Al mismo tiempo, se buscó referencial bibliográfico, en el sentido de discutir la condición de la mujer, de la política y de la vida sociocultural del país en el período histórico en que Alzira Vargas actuó. De los documentos estudiados, se abren innumerables posibilidades de interpretaciones y cuestionamientos sobre la real importancia y participación de una mujer que, siendo el padre, Getúlio Vargas, el presidente del país, tenga ella depositaria de la confianza y complicidad en momentos de extrema tensión, dudas y conflictos políticos en los ámbitos nacional e internacional. La cantidad de registros históricos, ya sean documentos oficiales, periódicos, revistas, vídeos o en audios no deja margen para dudas en cuanto a la presencia constante y discreta de la asesora Alzira Vargas y, en otros momentos, articuladora de la nación con otros países. La posibilidad de conocer a esta mujer que, en ambiente predominantemente masculino ocupó espacios importantes en momentos históricos cruciales para Brasil, instiga la búsqueda de conocerla y problematizar su trayectoria como figura femenina marcante en la historia del país, principal motivación de la presente investigación

Palabras claves: Alzira Vargas; género; Getúlio Vargas; la política; mujer.

\begin{abstract}
This article aim to approach the historical trajectory of Alzira Sarmanho Vargas on the political life of Brazil, at Getúlio Vargas' administration (1930-1945 and 1951-1954), in the sense of show her performance while a significant female figure of this period. The metodology used is constituted of researches on original sources, belonging of the patrimony of Getúlio Vargas' Museum, in the city of São Borja, on the Center of Search and Historical Documentation of Contemporary History of Brazil (CPDOC), of Getúlios Vargas', where it is laid up the personal archive of Alzira Sarmanho Vargas. Concomitantly, it was searched a bibliographic reference in the sense of problematize the woman's condition, of politic and the sociocultural life of the country on the historical period where Alzira Vargas had performed. About the documents studied, are innumerable possibilities of interpretation and questioning about the real importance and participation of a woman that, being daughter of Getúlio Vargas, the presidente of the country, he deposited on Alzira his confidence and complicity in moments of extreme tension, doubts and political conflicts in the national and international context. The amount of historical records, be them official documents, jornals, magazines, videos or audio don't let margin to doubts about a constant and discret presence of the advisor Alzira Vargas and in another moments, articulator of the nation with another countries. The possibility of know this woman that, in a predominantly male middle occupied important spaces on crucial historical moments to Brazil, stimulate the search of know her and to problematize her trajectory while a striking female figure on the history of the country, main motivation of this search.
\end{abstract}

Keywords: Alzira Vargas; gender; Getúlio Vargas; politic; woman.

\title{
1. Introdução
}

O presente artigo visa expor a participação da gaúcha Alzira Sarmanho Vargas na vida política brasileira, no período histórico nacional identificado como Governos Vargas, iniciado em 1930 e interrompido em 1945 e, por meio do voto popular, entre os anos de 1951 até 1954.

Busca-se com este estudo, uma reflexão inicial sobre a figura de Alzira Vargas no meio familiar e político do período, suas percepções e vivências no interior de um mundo de 
poder e de domínio predominantemente masculino, suas estratégias pessoais para a ocupação de espaços, bem como as suas demonstrações de inconformismo diante da postura e do comportamento das mulheres, conforme declarado por Alzira Vargas no filme realizado na $2^{\mathrm{a}}$ Oficina de Produção Audiovisual do Núcleo de Audiovisual e Documentário da Fundação Getúlio Vargas (FGV), do Centro de Pesquisa e Documentação de História Contemporânea do Brasil (CPDOC), "Eu ficava indignada. Eu não me conformava em ficar lá tomando chazinho, batendo papo vazio. Aquilo para mim não tinha sentido." (VARGAS, 2015).

Quando optava por tornar públicas suas ideias, sabia das consequências. Estas recebiam críticas, e não ignorava a existência de opressão por defendê-las. Era vigiada, sofria intimidações na universidade, foi odiada por grupos de ideologia política contrárias às que defendia e, inclusive, por aqueles que compartilhavam do mesmo pensamento. citar livro passagem universidade.

Durante sua participação no meio político brasileiro, Alzira Vargas desempenhou funções que foram de secretária, tradutora de documentos, decodificadora de mensagens cifradas, arquivista, interlocutora entre o povo e o governo, porta-voz do Brasil em Washington, entre outras funções ocupadas após o seu casamento com Ernani Amaral Peixoto, em 1939. Mas, não se limitou a cargos burocráticos e intelectuais, foi ainda responsável pela articulação para organização do Partido Trabalhista Brasileiro, fundado em 1945.

Assim, pensa-se que conhecer Alzira Vargas, uma mulher que fugia à regra da personagem feminina moldada socialmente, que tinha ideias próprias, que foi militante e articuladora política, com grande bagagem intelectual formal, filha, assistente e confidente de um presidente da República, e que, após o término da Era Vargas manteve o espólio documental do presidente por mais de duas décadas, conforme Nedel (2008) explica no IX Encontro Estadual de História, em Porto Alegre, possibilitando o acesso a um acervo que, segundo Nedel (2008), "Não fosse em si mesma relevante, a proximidade de Alzira Vargas com os núcleos de poder também redobra o potencial interesse de seu arquivo entre os historiadores e cientistas sociais, [...]" (NEDEL, 2008, p. 1), permite avançar sobre a história do Brasil daquele período e evidenciar que ela foi um personagem dos mais emblemáticas do período histórico analisado e que, apesar disso, a história oficial a remeteu aos bastidores dos acontecimentos.

\section{Metodologia}


As investigações sobre Alzira Vargas, realizadas após o planejamento da pesquisa e a construção de um portfólio inicial de fontes, mostraram-se um desafio em função das escassas opções de fontes de pesquisa bibliográfica específicas.

Com vistas a manter o eixo de pesquisa definido, operou-se o arbitramento dos conceitos principais a serem buscados durante a realização da pesquisa, como a compreensão sobre a situação da mulher com uma visão ampliada sobre aspectos sociais, filosóficos e históricos no âmbito familiar e público da mulher Alzira Vargas em ambiente dominado pelo masculino.

Para a obtenção dos resultados foram definidas estratégias de pesquisa que viabilizassem o acesso a informações seguras quanto ao reconhecimento das fontes. Uma das estratégias foi o estudo das fontes primárias mantidas sob a guarda do Museu Getúlio Vargas, em São Borja, e, para tal, foram procedidas as formalidades necessárias, com a informação de data, horário, número de pesquisadores, assunto e objetivos da pesquisa, documentos desejados, entre outros. Entretanto, não houve a plena recepção do requerido museu, restando o acesso a documentos que, em sua maioria, não corresponderam às expectativas produzidas após a visualização do volume de documentos mantidos em ambiente controlado.

Decorrente da escassez de fontes houve a necessidade de revisar o planejamento da pesquisa. Tal situação acabou por conduzir a pesquisa para a internet e bibliografia em documentos impressos, como o livro Getúlio Vargas, meu pai. Neste novo rumo, foi localizado o arquivo pessoal de Alzira Vargas no Centro de Pesquisa e Documentação de História Contemporânea do Brasil (CPDOC), espaço virtual da Fundação Getúlio Vargas. O volume de documentos originais disponíveis em meio digital é considerável, com acesso irrestrito, com espaço para solicitação de auxílio para localização, de orientações ou obtenção de cópia digital. Importante salientar que os documentos compõem o Dicionário Histórico Biográfico Brasileiro, elaborado e organizado pelo CPDCO.

Além dos documentos disponíveis no Museu Getúlio Vargas e no CPDOC, a leitura das memórias de Alzira Vargas, onde constam suas percepções dos fatos no momento em que ocorriam, produziu uma aproximação entre a pesquisada e as autoras, tornando as palavras lidas mais concretas. Do mesmo modo, a audição de suas palavras ou a visão de sua imagem em vídeo gerou a sensação de redução da distância temporal e despertou no grupo de pesquisa certa inquietação mental, manifestada em questionamentos que surgiram sobre as mudanças efetivamente ocorridas quando se trata da mulher nos espaços públicos, especificamente na política, desde Alzira Vargas até o tempo presente.

\section{Resultado e discussão.}




\subsection{Alzira Vargas em família}

Alzira Sarmanho Vargas, filha de Getúlio Vargas e Darcy Sarmanho Vargas, nasceu em 22 de novembro de 1914, em São Borja, sendo a terceira filha do casal. Morou até os oito anos de idade em sua cidade natal quando mudou-se para Porto Alegre. Aos dezesseis anos de idade passa a morar no Rio de Janeiro, onde cursou Direito, na Faculdade de Direito, e em pouco tempo começou a atuar como arquivista do pai. No último ano do curso foi nomeada auxiliar de gabinete de Getúlio Vargas. Aos 25 anos se casou com Ernani Amaral Peixoto, militar e político, com quem teve uma filha, Celina Vargas do Amaral Peixoto.

A relação familiar que existia entre Alzira e o pai é contada no livro "Getúlio Vargas, meu pai", lançado originalmente em 1960. Nele, Alzira Vargas relata a convivência familiar e profissional com seu pai. Alzira, filha e assistente, era alguém que Getúlio confiava e queria por perto, como se pode perceber no trecho a seguir, “[...] O que sei é que todas as vezes em que ficava longe dele muito tempo, me chamava de volta”. (VARGAS, 1960, p. 366). A ligação entre pai e filha era tão próxima, respeitosa e sincera que os papéis de filha e funcionária se confundem, de um modo que é difícil perceber onde uma se destaca mais que a outra.

Em toda sua vida Alzira Vargas esteve ligada ao pai, mesmo que não estivesse presente, se comunicavam por cartas e reforçavam ainda mais o laço familiar. Porém, a pesquisa mostrou que a mãe, Senhora Darcy Vargas também representou figura importante para a atuação de Alzira Vargas como herdeira dos projetos assistenciais desenvolvidos pela mãe.

\subsection{A política brasileira e Alzira Vargas}

No Brasil, após os movimentos políticos de 1930, o ambiente político nacional se encontrava instável, conforme explicado em "História do Brasil por Bóris Fausto" "Getúlio teve que enfrentar problemas internos do seu governo, das forças que o apoiavam, e problemas externos, da oposição”. (FAUSTO, 2002).

Em um ambiente de conflitos ideológicos, de interesses distintos e de poder, as prisões sob acusações de adesão à ideologia comunista não eram fatos raros. Segundo o arquivo pessoal de Alzira Vargas, mantido no Centro de Pesquisa e Documentação de História Contemporânea do Brasil (CPDOC), a jovem estudante universitária tinha participação ativa em passeatas, assim como de intervir junto ao pai para soltura de professores feitos prisioneiros, o que exige a menção a sua vida de militante estudantil iniciada em Porto Alegre entre 1928 e 1930, o que lhe rendeu intensas e repetidas investidas da mídia ligando-a ao comunismo, sobre o que Alzira Vargas escreve em Getúlio Vargas, meu pai "Passei a 
respeitar a força da propaganda dirigida. Esta havia decretado: "Alzira, a filha do Presidente da República, estudante de direito, é comunista"." (VARGAS, 2017, p. 169).

É neste cenário que Alzira Vargas surge para o Brasil. Em janeiro de 1937 foi nomeada oficialmente como auxiliar de gabinete, passando a integrar o Gabinete Civil da Presidência, aos 23 anos de idade, quando cursava o último ano do curso de Direito. Sua presença como assessora, consultora, confidente, secretária, firmou-se ainda mais em 1938, em momento político de mudanças de regime.

O sítio virtual da Fundação Getúlio Vargas - CPDOC, afirma que "Com os canais institucionais interrompidos, Alzira somou às suas tarefas, como diria em seu depoimento, a função informal de interlocutora entre o povo e o governo" (COUTINHO, 2009, s/p).

Do pesquisado no CPDOC, é importante salientar que Alzira Vargas não atuou apenas nos tratos burocráticos ou de assessoria ao Presidente. Consta o relato da participação ativa na resistência a ataque ao palácio Guanabara, em 11 de maio de 1938, quando atuou junto às comunicações telefônicas com os chefes dos órgãos de segurança.

Casada com o interventor do estado do Rio de Janeiro, ocupou-se como interlocutora entre o Presidente do Brasil e o presidente estadunidense Franklin Roosevelt, o que dá a perspectiva de sua capacidade de atuação política, ainda mais se analisadas as peculiaridades mundiais da época.

Mas, sua atuação não se resumia àquelas ligadas ao palácio presidencial. Conforme o arquivo mantido na Fundação Getúlio Vargas, suas ações estenderam-se na área da educação, criando instituições importantes até os dias atuais, como a Fundação Anchieta. Entretanto, em áudio disponível na internet, intitulado A Bacharel e o Presidente, Alzira declara: “[...] outro dia estava comentando com o Ernani. Disse: “engraçado, eu tenho a impressão de que nada do que eu fiz tem valor, porque como eu nunca quis pessoalizar nada, as minhas obras sumiram" (VARGAS, 2015).

As palavras de Alzira nos deixam evidente a ação do sistema de poder sobre as mulheres durante aquele período, evidenciado em suas lembranças: "Habituei-me, assim, a enxergar sem ver, a ouvir sem entender. Habituei-me a calar. Habituei-me a um silêncio que hoje pesa sobre meus nervos, cansados de perdoar sem esquecer.”. (VARGAS,2017, p. 44).

A participação de Alzira Vargas no mundo político, espaço masculino e centralizado na figura do pai, parece, contudo, não ter sido empecilho para impedi-la de assumir responsabilidades. Ao contrário, não se omitiu de atender pedido do pai para agir como articuladora na formação de partido político visando manter as bases aliadas do governo getulista, e que mais tarde o faria presidente novamente. Entretanto, não há registro de 
afiliação partidária em sua vida, conforme arquivo do CPDOC.

Em 1945 ocorre a queda de Vargas. Exilado em São Borja, Alzira mantém intensa correspondência com o pai, mantendo-o inteirado dos acontecimentos do meio político e, em função da saída de Amaral Peixoto, seu marido, do governo fluminense, Alzira se desligou de cargos que ocupava em instituições sociais. Dentre outras, consta a Legião Brasileira de Assistência - LBA, a Fundação do Menor e a Comissão do Bem-Estar do Menor, vinculada ao Ministério do Trabalho, segundo os arquivos da FGV/CPDO.

Com o retorno do pai ao poder da República em 1954 e do marido ao governo do Rio de Janeiro, retomou funções oficiais, integrando delegações brasileiras às conferências internacionais do Trabalho.

Inegável que ocupou espaços e definiu posturas que lhe garantiam o papel de principal auxiliar de Vargas. Em áudio disponível em espaço virtual já citado, fica explícita sua estratégia para definir sua participação, desde em mesas de reuniões, até confidências do Presidente. Quando questionada sobre como ela teria chegado a ter sobre ele certa ascensão, responde:

Foi gradual e lenta a maneira pela qual eu me impus a ele. Não posso dizer a você que ele tenha me descoberto. Mas, aquela vida de trabalho, de uma ocupação sempre me atraiu. Então, eu comecei, como disse a você, sendo o mata borrão dele. Nunca propriamente procurei ser o braço direito dele, ao contrário. Me omiti o mais possível porque eu sabia o que era e eu conhecia a importância que se dava a mulher do Rio Grande nesta época. (VARGAS, 2015).

Declara na entrevista citada acima que a confiança conquistada com o presidente lhe proporcionava ouvir, falar e conversar sobre assuntos que nenhuma outra pessoa tinha abertura, ou ainda, presenciar conversas porque o nível de confiança em seu silêncio para o que ouvia, era tal que não havia omissões a ela, o que lhe causava medo. Não é difícil pensar que o que lhe era conhecido, não eram situações simples e de pouco interesse para pessoas de muita influência.

Em seus relatos, chama a atenção colocações em relação a seu gênero ser motivo de observações, tanto familiares quanto do meio político, tais como o de uma tia que "[...] teria nascido feito homem." E, em outra ocasião, o pai teria recebido comentário de um grande amigo que teria dito: “Getúlio, não achas que esta tua filha está ficando muito sabida?", ao que respondeu, "Ele quer que eu seja sábia e não sabida”. (VARGAS, 2017, P. 93).

No acervo do Museu Getúlio Vargas, em São Borja, no suplemento da REVISTA DO GLOBO (1950, p. 50, 51), Alzira faz narrativa do golpe Integralista de 1938. Conforme o repórter autor da matéria jornalística, não houve a interferência do pai. O relato leva o leitor a 
criar a imagem mental da aflição vivida durante o evento, o que pode ser remetida à habilidade da narradora em expor um cenário com riqueza de detalhes, clareza na conexão dos momentos e capacidade de análise dos eventos, características que podem ser dadas a uma memória criada a partir dos fatos vividos.

Ainda, há de se observar sobre o fato de Alzira Vargas ser uma mulher jovem, de pequeno porte físico, o que não a impediu de pegar em armas e fazer uso destas em defesa do Palácio Guanabara. Tal atitude não era um fato corriqueiro para a mulher daquele período, mas tratava-se de Alzira Vargas. Inclusive, pode ser destacada uma leve crítica à condição de inoperância da irmã Jandira Vargas durante o confronto.

Consta no arquivo do CPDOC/FGV o relato de que, com a crescente luta para que o Getúlio renunciasse, Alzira tomou conhecimento sobre um apontamento do Presidente, sendo identificado o mesmo trecho em Getúlio Vargas, meu pai, onde consta: “Á sanha dos meus inimigos deixo o legado de minha morte.” (VARGAS, 2017, p. 427). Com o rascunho em mãos, indo buscar junto ao pai alguma indicação de suas intenções, quando o Presidente respondeu: "[...] Sua bisbilhoteira. Não é nada disso que você está pensando. Você me conhece, e ficou com o papel”. (VARGAS, 2017, p. 427).

Mas, no decorrer dos estudos dos documentos, tanto no arquivo da FGV/CPDOC, como nas memórias de Alzira, que compõe o livro Getúlio Vargas, meu pai, foi possível identificar a presença marcante de Alzira Vargas no momento crucial da Era Vargas. No dia 24 de agosto, após eventos dados como interligados, o Presidente convoca seu ministério para reunião, assim como Alzira e seu esposo. Consta que, durante a reunião, que tinha como pauta a proposta de renúncia de seu pai, ela intervém fortemente, como quando relata:

O general Zenóbio da Costa estava falando: dizia que era incontrolável o movimento contra Getúlio Vargas. Não me contive mais, pedi desculpas ao meu pai e dei um soco na mesa, dirigindo-me diretamente ao general Zenóbio: "Não é somente a sua vida nem a de meu pai que está em jogo. A minha e a de minhas crianças também, por isso dou-me o direito de falar. (VARGAS, 2015, p. 431)

Entretanto, provoca uma certa estranheza que parte da historiografia parece não ter a mesma interpretação sobre a participação de Alzira em eventos historicamente consagrados para os cientistas, como é o caso das horas finais da Era Vargas. Isto está explícito em Fausto (2006, p. 189,190) que, ao abordar sobre a pressão que o setor militar impunha a Getúlio Vargas, culminando na fatídica reunião do dia 24 de agosto, Alzira mereceu tão somente uma menção a seu nome juntamente com mais três pessoas, não por acaso, homens.

Nela, os ministros militares foram muito hesitantes, optando obliquamente pela renúncia, apesar dos apelos do ministro da Justiça, Tancredo Neves, no sentido de que eles mostrassem disposição de sustentar o governo. Osvaldo Aranha declarou-se solidário com Getúlio em qualquer circunstância, apontou três hipóteses de resposta 
às pressões e disse que tudo dependia da decisão do presidente. Alzira Vargas fez um apelo à resistência, apoiada entre outros por Manuel Vargas, Danton Coelho e o general Caiado de Castro. (FAUSTO, 2006, p. 190).

Disto, podemos apreender que Alzira não via e não recebia limites para manifestar seus pontos de vista de situação tão sérias e graves no mundo da política, inclusive para abandonar a tal reunião antes do seu fim. Na sequência, após receber orientações do pai, em presença do irmão, sobre uma chave de cofre, o qual deveria ser aberto caso ocorresse algo com o Presidente. Em pouco tempo depois, foi informada por militar que decidiram pela saída definitiva de Getúlio, contrariando a decisão ministerial anterior, encerrando com o suicídio do Presidente e pai Getúlio Vargas.

Em 1955 deixa de ser a primeira dama do estado do Rio de Janeiro, sendo seu marido nomeado embaixador do Brasil em Washington, até o ano de 1959. Neste momento, mostrase, no mínimo, curiosa a correspondência mantida com Alzira, na qual está recomendado que repensasse a possibilidade em função de o remetente entender como uma armadilha tal cargo, citando que a capital de Portugal seria o mais adequado. Conclui-se que não foi considerada a recomendação recebida.

Após assumir a função de embaixatriz, identifica-se no acervo digital depositado no CPDOC/FGV inúmeras correspondências entre órgãos públicos, instituições de ensino, intelectuais e, destacamos, com Sara Kubitschek, outra mulher singular no mundo da política brasileira, onde Alzira informa sobre envio ao Brasil de bonecas produzidas por mães norte americanas, com recomendações sobre a quem destinar. Destes documentos, fica claro que o período que desempenhou as funções na embaixada brasileira nos Estados Unidos, foram atuantes, com ligações bastante próximas de autoridades daquele país.

No ano de 1960, de volta ao Brasil, publicou suas lembranças em livro intitulado Getúlio Vargas, meu pai. Além disso, ocupou a função antes da sua mãe, na Casa do Pequeno Jornaleiro, foi Presidente da Fundação Anchieta entre 1940 e 1945, como já dito, Membro da Comissão Nacional do Bem-Estar Social, de 1951 até 1954, Membro de Delegação, na Conferência Internacional do Trabalho, no ano de 1952, Presidente da Fundação Darcy Vargas no período de 1968 a 1992.

Entretanto, o mundo do poder político a acompanhou por muito tempo em razão de o marido ocupar diversos espaços políticos. Durante este tempo desenvolveu e se envolveu em diversos projetos, concretizando, por exemplo, a criação da Escola de Enfermagem do Rio de Janeiro e a Escola de Serviço Social, integradas a Universidade Federal Fluminense, a Maternidade Divina Providência, em Petrópolis-RJ. No período da Grande Guerra Mundial, 
acumulou a direção do Departamento Assistencial do Distrito Federal, da Legião Brasileira de Assistência no estado fluminense e das Voluntárias da Defesa Passiva do ano de 1942 até o ano de 1945.

Através das palavras da própria Alzira, citadas anteriormente, suas obras parecem ter sumido nas gavetas empoeiradas da história. Mas, a pesquisa sobre a sua pessoa e em seu tempo, nos traz à tona uma figura ciente de que estava em ambiente que não lhe favorecia, com personagens que não lhe facilitariam a atuação e, para tanto, desenvolveu estratégias de "sobrevivência" e de ocupação de espaços.

Faleceu no Rio de Janeiro, no dia 26 de janeiro de 1992.

\subsection{A condição da mulher na Era Vargas, a mulher Alzira Vargas}

A mulher brasileira atualmente goza de melhores condições que em épocas passadas, embora exista pontos que precisam ser discutidos e campos a serem conquistados, admite-se que os tempos são outros. E, é olhando para trás que vemos o caminho daquelas que de uma maneira ou de outra, contribuíram para marcar o seu espaço como mulher em um país dominado pelo patriarcado.

Uma dessas figuras foi Alzira Vargas, e nesse trecho da pesquisa veremos as condições das mulheres brasileiras e dela própria, no contexto da Era Vargas. Assim como escreve Beauvoir, "[...] nenhuma coletividade se define nunca como Uma sem colocar imediatamente a Outra diante de si". (BEAUVOIR, 1970. p. 12), pondera-se a partir da colocação que a estrutura social brasileira tem em seu âmago uma longa história de disparidade entre os sexos. Se a História por muito tempo se ocupou das figuras masculinas, do poder exercido pelo homem no campo político e social, é premente que o outro lado da coletividade seja evidenciado para que sejam definidas as particularidades de ambos os lados.

Tratar algumas dessas características da parcela da coletividade brasileira, a qual, por muito tempo, esteve fora do campo historiográfico, sabendo que não existe um perfil único de mulher atualmente, assim como também não houve no período analisado, é necessário dada a amplitude do tema. Para tal, serão mencionadas algumas peculiaridades que estavam em voga no universo feminino pois, estas características são pertinentes para demonstrar como Alzira foi percebida na sua condição de mulher por seus contemporâneos.

Dadas as fontes, identificou-se que um dos principais pontos de discussão diz respeito ao trabalho desempenhado pela mulher e como esse fator conseguiu transformar as características do comportamento sociocultural feminino no período em questão. À luz dessa discussão podemos perceber as diferenças entre as mulheres que saíram do 'lar' (por necessidade e/ou por obrigação de prover o sustento de si e dos filhos) e aquelas que 
assumiram o papel socialmente aceito para época. Também se constatou uma distinção entre classes sociais, demonstrando a pluralidade socioeconômica que o país já vinha revelando a mais tempo do que a historiografia de outrora menciona, como se refere Fonseca,

\begin{abstract}
A norma oficial ditava que a mulher devia ser resguardada em casa, se ocupando dos afazeres domésticos, enquanto que os homens asseguravam o sustento da família trabalhando no espaço da rua. Longe de retratar a realidade, tratava-se de um estereótipo calcado nos valores da elite colonial, e muitas vezes espelhado nos relatos de viajantes europeus, que serviam como instrumento ideológico para marcar a distinção entre as burguesas e as pobres. Basta aproximar-se da realidade de outrora para constatar que as mulheres pobres sempre trabalharam fora de casa. (FONSECA, 2012. p. 517)
\end{abstract}

Temos então, a partir do período Vargas iniciado em 1930 até 1945, e em seu segundo governo de 1950 a 1954, um marco para todas as mulheres brasileiras, definido através do direito ao voto nas decisões políticas do país, conquistado em 24 de fevereiro de 1932.

Em 1928 foi criado o Comitê das Mulheres Trabalhadoras, umas das primeiras associações voltadas para as necessidades das mulheres que trabalhavam no contexto das indústrias têxteis, ou seja, fora de seus lares. Apesar de serem a maioria da mão-de-obra nesses ambientes, eram excluídas dos sindicatos, pois nestes ambientes não contavam com a força de voto. E também, ressalta-se no estudo, que as reuniões dos sindicatos não foram feitas para contemplar a jornada dupla da trabalhadora, que ao voltar para casa, essa mulher ainda assumia sua outra faceta, a mulher do lar, e todos os seus encargos. Situação demonstrada por Sardenberg, que afirma "[...] dessa maneira, "o mundo sindical no Brasil no início do Século Vinte", como o mundo da política das elites, permaneceu esmagadoramente masculino". (SARDENBERG et.al, 2000. p. 05, grifo da autora).

Outro ponto importante, e ainda discutido atualmente, é a diferença salarial. Para o contexto da época a mulher trabalhadora deveria ganhar menos porque sua renda era complementar. Beauvoir também advoga a esse respeito quando diz, "[...] ora, a mulher sempre foi, senão a escrava do homem ao menos sua vassala; os dois sexos nunca partilharam o mundo em igualdade de condições." (BEAUVOIR, 1970. p. 14).

Devido aos salários inferiores e o avanço do capitalismo, o número de mulheres trabalhadoras era maior nas fábricas, o que acarretou problemas. Em 1931, o presidente Getúlio Vargas recebeu uma reclamação dos trabalhadores da indústria têxtil de São Paulo, onde manifestavam descontentamento em relação ao número expressivo de mulheres no trabalho, e que isto causava desemprego aos homens. A resposta do Estado Novo a esse anseio seria conduzir ambos, homens e mulheres, aos seus papéis "tradicionais" na sociedade. O tradicional implícito a homens pais/provedores e mulheres mães/do lar. Porém, de modo 
controverso, regulamenta o trabalho feminino nas indústrias e comércios com a legislação social e trabalhista, através do Decreto 21.417A, de 17 de maio de 1932.

O antagonismo do governo Vargas, a ideia jargão de 'pai dos pobres e mãe dos ricos', foi propulsor tanto de mulheres saindo para o trabalho como aquelas que ficaram em seus lares. Mas, é preciso não cometer o equívoco de acreditar ser esta uma questão de escolha, a vida da mulher nas fábricas e no mundo do trabalho em geral era difícil e exigia da mulher muito mais que apenas uma escolha, exigia uma postura diante da sociedade, pois, segundo Hirata et al. $(2009, s / p)$, ao tratar do poder do feminismo, diz que a marca da mulher livre e a mulher pública eram relacionadas, e isto a colocava como alvo de escândalos, como foram situações vividas por muitas mulheres que ousaram questionar a hierarquia dos sexos existente e práticas pelas autoridades, evidentemente homens.

Em relação à profissão de educadora, para as mulheres havia um limite, qual seja ser professora das primeiras letras, as "normalistas", pois os demais graus escolares eram exercidos por homens, de acordo com Nahes Semiramis (SEMIRAMIS, 2007, p. 28). A autora diz ainda que a função de professora envolveria a mulher como mãe, mesmo que os filhos (alunos) não fossem dela, e ainda mais, que o cuidar de crianças estava ligado ao âmbito caseiro, então, embora sendo uma profissão, o seu caráter e suas regras colocava a mulher (professora, trabalhadora) no "seu lugar" na sociedade.

Nesse âmbito de mulher da Era Vargas, podemos contextualizar através da primeiradama Darcy Sarmanho Vargas, outro perfil de mulher. A mãe de Alzira Vargas, teve um papel ligado ao lado maternal, ao auxílio da mulher/mãe e das crianças, se envolveu e encabeçou várias entidades assistenciais como a Casa do Pequeno Jornaleiro e Legião Brasileira da Assistência (LBA), criada em 1942, para prestar amparo aos familiares e soldados que lutaram na Segunda Guerra Mundial, e isso era um traço marcante das mulheres da elite no período. Ela foi uma mulher do seu tempo e do seu estrato social e dessa forma, "[...] foi no desempenho das funções de esposa e mãe, que Darcy Vargas desenvolveu formas de atuação e de participação na política, inclusive, mediante a criação de obras sociais e assistenciais". (SIMILI, 2004, p. 02).

Semelhante papel teve a irmã mais velha de Alzira, Jandira Vargas, esta foi também, uma mulher aos moldes tradicionais, conforme se constatou na pesquisa na documentação do acervo do Museu Getúlio Vargas, em São Borja. Jandira não se formou no ensino superior como sua irmã mais nova, casou por volta dos 25 anos, teve filhos e sua vida foi voltada para a casa. Um comportamento que pode ser explicado pela autora Pinsky, em a História das Mulheres no Brasil: 
Ser mãe, esposa e dona de casa era considerado o destino natural das mulheres. Na ideologia dos Anos Dourados, maternidade, casamento e dedicação ao lar faziam parte da essência feminina; sem história, sem possibilidades de contestação. (PINSKY, 2012. p. 609).

Então, disto podemos compreender que o universo das mulheres não era apenas moldado pelo homem. O exemplo estava em casa, a menina se espelhava na mãe, logo seu destino era uma vida parecida ao de sua progenitora, e assim foi com Darcy e Jandira Vargas.

Porém, a pesquisa demonstra que para Alzira Vargas o exemplo mais nítido foi seu pai, e isso deu a ela um perfil diferente daquele da maioria das mulheres do período, e não que Alzira se visse como um homem, mas em alguns momentos foi assim considerada por outros justamente por realizar o trabalho tão "bem" quanto um.

Apoiada pelo seu pai, Alzira graduou-se em Direito pela Faculdade de Direito do Rio de Janeiro, quando ainda a formação superior era um fato incomum para mulheres da elite. Como guardiã das memórias de seu pai, ela relata que Vargas tinha uma concepção moderna a respeito da mulher, o que está demonstrado por Gomes, ao citar trecho de entrevista concedida por Alzira, que diz: "[...] Mulher, para ele, fala D. Alzira, tinha que saber três coisas: datilografia, dirigir automóvel e falar inglês." (GOMES, 1996. p.9). E Alzira não fugiu a nenhuma das três regras: dirigia, falava inglês, datilografava, além de fazer companhia em suas campereadas, quando buscava o sossego nas estâncias de São Borja.

\section{Conclusões}

A intenção do texto não é produzir críticas ou julgamentos às mulheres, especialmente àquelas que se mantinham unicamente, ou que ainda permanecem, no exercício das atividades domésticas. O que a pesquisa elucida é que, para o contexto de 1930 a 1954, o ideal de ser mulher, corroborado pela sociedade, pela literatura e estudos da época, e principalmente pelos homens, era a dona de casa, a mãe, mas não aplicável em Alzira Sarmanho Vargas.

Entretanto, devemos destacar que Alzira Vargas tinha o ímpeto de descumprir normas sociais. Como detalhe do seu perfil incomum, e começando por decisões sobre o seu corpo, evidencia-se as suas escolhas na vestimenta, elementos ligados à beleza e posição social feminina. Não usou vestido de noiva em seu casamento, raramente usava chapéu, artigo da moda entre as mulheres da época, usava calças, sapatos com altura mediana, fumante por um período, cavalgava com habilidade, realizava atividades ligadas à pecuária, favorável ao divórcio, ou seja, parecia não lhe incomodar não atender à imagem idealizada pela sociedade para a mulher. Mas, certamente que a ligação íntima mantida com o meio político, primeiro com seu pai, e depois e com seu marido motivou a pesquisa. 
Poderá o leitor pensar: "mas ela era filha do presidente!". Sim, ela foi. E Jandira também foi, e mesmo assim vemos duas mulheres diferentes, dois perfis diferentes de vida da mulher no contexto estudado.

Como já dito, a intenção do estudo não é categorizar, e tão pouco julgar aquelas que nos antecederam. Mas, é fundamental suscitar que a mulher brasileira é parte fundamental da História do país, mesmo à sombra dos homens e de costumes sociais engessados, elas lutaram para se inserir no contexto público-político, fabril, sindical, educacional etc., território masculino. E para tal intento, Alzira descobriu e desenvolveu os meios de tornar-se a "segunda consciência" do Presidente, expressão que o próprio passou a usar para com a sua assitente, de acordo com a pesquisada.

A vida pública-política de Alzira Vargas passou por momentos extremos. O que se obtém das leituras sobre ela, das análises de imagens, dos áudios, da bibliografia utilizada é que foi uma mulher observadora, com mente inquieta, questionadora, determinada, com clareza de pensamento, habilidosa na condução de assuntos delicados e perigosos, e todas estas características desenvolvidas, ou potencializadas com o passar do tempo, visando levar a cabo o projeto político do pai.

\section{Referências}

BEAUVOIR, Simone de. O segundo sexo I Fatos e Mitos. 4 ed. São Paulo: Difusão Européia do Livro, 1970. p. 12. Disponível em: http://brasil.indymedia.org/media/2008/01/409660.pdf. Acesso em: 17 jun. 2017.

BRASIL. Decreto n ${ }^{\circ}$ 21.417A, de 17 de maio de 1932. Regula as condições do trabalho nos estabelecimentos industriais e comerciais. Diário Oficial da República Federativa do Brasil. Brasília, 1934. Disponível em: http://www2.camara.leg.br/legin/fed/decret/19301939/decreto-21417-17-maio-1932-559563-publicacaooriginal-81852-pe.html. Acesso em: 27 out. 2017.

FAUSTO, Bóris. História do Brasil por Boris Fausto. Disponível em: https://tvescola.mec.gov.br/tve/video/historia-do-brasil-por-boris-fausto-a-era-vargas. Acesso em 27 out. 2017.

. A Era Vargas: dos anos 20 a 1945. Semana da Arte Moderna. Disponível em: http://cpdoc.fgv.br/producao/dossies/AEraVargas1/anos20/ArteECultura/SemanaDaArteMod erna. Acesso em 16 jun. 2017.

A Era Vargas: dos anos 20 a 1945. Anos de Incerteza (1930-1937). No país dos tenentes. Disponível em: http://cpdoc.fgv.br/producao/dossies/AEraVargas1/anos3037/PaisDosTenentes. Acesso em: 17 jun. 2017.

. Centro de Pesquisa e Documentação de História Contemporânea do Brasil (CPDOC). Biografias. Alzira Vargas. Rio de Janeiro - RJ. Disponível em: 
https://cpdoc.fgv.br/producao/dossies/AEraVargas2/biografias/alzira_vargas_do_amaral_peix oto. Acesso em: 17 jun. 2017.

Núcleo de Audiovisual e Documentário. A bacharel e o presidente. Publicado em 6 abr 2016. Disponível em: https://www.youtube.com/watch?v=5y_oNafW2g0. Acesso em: 17 jun. 2017.

- A guardiã da memória. Acervo - Revista do Arquivo Nacional, Rio de Janeiro, v.9, $\mathrm{n}^{\mathrm{o}}$ 1/2, p.17-30, jan./dez. 1996. Disponível em:

http://bibliotecadigital.fgv.br/dspace/bitstream/handle/10438/6836/538.pdf?sequence=1\&isAl lowed=yAcesso em 18 jun. 2017.

GOMES, Ângela de Castro. A guardiã da memória. Acervo- Revista do Arquivo Nacional, Rio de Janeiro, v.9, nº 1/2, p.17-30, jan./dez. 1996. Disponível em:

http://cpdoc.fgv.br/producao_intelectual/arq/538.pdf . Acesso em: 11 jun. 2017.

HIRATA, Helena et al. DIONÁRIO CRÍTICO DO FEMINISMO. Tradução de Helena Hirata et al. (Orgs.). São Paulo. Ed. UNESP. 2009. Título original: Dictionnaire critique du fêminisme. Disponível em: https://pt.scribd.com/doc/212648237/164874353-DicionarioCritico-Do-Feminismo. Acesso em: 20 out. 2017.

NEDEL, Letícia. Os papéis de Alzira Vargas: biografia política de um arquivo pessoal. In: IX ENCONTRO ESTATUAL DE HISTÓRIA. Porto Alegre, 2008. p.1. Disponível em: eeh2008.anpuh-rs.org.br/resources/.../1212373536_ARQUIVO_anpuh_avap.pdf. Acesso em: 27 out. 2017.

PEIXOTO. Alzira Vargas do Amaral. Getúlio Vargas, meu pai. Manuscrito - Esboços originais. Disponível em:

http://docvirt.com/docreader.net/docreader.aspx?bib=FGV_AVAP_GV\&pasta=AVAP\%20gv \%20gvmp\%201956.00.00/. Acesso em: 20 jun. 2017.

PINSKY, Carla Bassanezi. Mulheres dos Anos Dourados. In. . História das mulheres no Brasil. DEL PRIORE, Mary (org). 10 ed. São Paulo: Contexto, 2012. p. 607 - 639.

REVISTA DO GLOBO - Suplemento. Subsídios para as Memórias de Getúlio Vargas. Acervo Museu Getúlio Vargas. 1950. p. 50,51.

SARDENBERG, Cecília Maria Bacellar et al. Mulheres e Sindicato: Presença feminina no Sindtêxtil - Bahia nos anos 50. In. VI Simpósio Baiano de Pesquisadoras (es) sobre Mulher e Relações de Gênero. Núcleo de Estudo Interdisciplinares sobre a mulher NEIM/ Universidade Federal da Bahia, 2000. p. 5. Disponível em:

https://repositorio.ufba.br/ri/bitstream/ri/6877/1/MULHERES\%20E\%20SINDICATOS.pdf. Acesso em: 18 jun. 2017.

SEMIRAMIS, Nahes. A Era Vargas: da revolução de 1930 à ditadura. In: Revista FON-FON: a imagem da mulher no Estado Novo (1937-1945). São Paulo: Arte e Ciência, 2007. p. 23 - 71. Disponível em: http://www.unimar.br/publicacoes/ftp/miolo_Fon_Fon.pdf. Acesso em: 17 jun. 2017. 
*SIMILI, Ivana Guilherme. A construção de uma personagem: a trajetória da primeira-dama Darcy Vargas (1930-1945). In. VII Seminário Internacional Fazendo Gênero, 7. VII Seminário Internacional Fazendo Gênero, Universidade Federal de Santa Catarina, Florianópolis, 2006. p. 2. Disponível em:

www.fazendogenero.ufsc.br/7/artigos/I/Ivana_Guilherme_Simili_42.pdf. Acesso em: 18 jun. 2017.

*A fonte também consta como material de pesquisa no Museu Getúlio Vargas.

VARGAS, Alzira. Getúlio Vargas, meu pai: memórias de Alzira Vargas do Amaral Peixoto/Alzira Vargas. - $1^{\text {a }}$ Ed. - Rio de Janeiro: Objetiva, 2017. (p. 44, 53, 77, 412-419, 427, 431).

VARGAS, Alzira. A Bacharel e o Presidente: Depoimento. 2016. Canal FGV. A Bacharel e o Presidente. Entrevista concedida a Naya Araujo. Disponível em:

https://www.youtube.com/watch?v=5y_oNafW2g0\&t=25s . Acesso em 27 jul. 2017. 